\title{
Aerosolized rhDNase in cystic fibrosis: effect on leucocyte proteases in sputum
}

\author{
Th. Rochat, F. Dayer Pastore, S.E. Schlegel-Haueter, \\ I. Filthuth, R. Auckenthaler, D. Belli, S. Suter
}

Aerosolized rhDNase in cystic fibrosis: effect on leucocyte proteases in sputum. Th. Rochat, F. Dayer Pastore, S.E. Schlegel-Haueter, I. Filthuth, R. Auckenthaler, D. Belli, S. Suter. (C)RS Journals Ltd 1996.

ABSTRACT: In cystic fibrosis (CF), large amounts of free leucocyte proteases are present in bronchial secretions, contributing to progressive lung damage. Recombinant, human deoxyribonuclease (rhDNase) is a new therapeutic agent that decreases sputum viscosity. However, deoxyribonuclease has been shown, in vitro, to release cationic enzymes from complexes with deoxyribonucleic acid (DNA). The present study was conducted to assess this effect in vivo.

Free human leucocyte elastase (HLE), human leucocyte cathepsin G (HCG), total chemotactic activity, and interleukin-8 (IL-8) were determined in sputum from eight patients before, during and after rhDNase treatment.

After 15 days of treatment, HLE activity increased by $81 \pm 44 \%$ (NS), and HCG by $189 \pm 70 \%(p<0.05)$. One week after stopping a 4-6 months treatment, HLE activity decreased by $35 \pm 18 \%(p<0.05)$, and HCG by $43 \pm 11 \%(p<0.05)$. Sputum bacterial density, chemotactic activity, and IL-8 concentration did not change.

Thus, treatment with rhDNase can indeed increase the activity of HLE and HCG in the bronchial secretions of CF patients, and this effect is still detectable after several months of treatment. If this can be shown to be clinically relevant, combination therapy of recombinant human deoxyribonuclease with protease inhibitors should be considered as an approach to the problem.

Eur Respir J., 1996, 9, 2200-2206.
Pulmonary Division and Infectious Disease Division. Depts of Medicine and of Pediatrics, University Hospital, Geneva, Switzerland.

Correspondence: T. Rochat

Division de Pneumologie

Hôpital Cantonal Universitaire CH-1211 Genève 14

Switzerland

Keywords: Cathepsin G

chemotaxis

cystic fibrosis

deoxyribonuclease

elastase

interleukin-8

Received: December 141995

Accepted after revision May 221996

This study was supported by grant No. 3236338.92 of the Swiss National Research Fundation, and by a research subvention from Roche Pharma International Ltd.
Chronic infection of the bronchial tree is a main feature of cystic fibrosis (CF), leading to the production of thick, abundant sputum in the airways. Recently, a significant therapeutic advance has occurred with the availability of commercialized recombinant human deoxyribonuclease (rhDNase), a product that dramatically reduces the viscosity of purulent bronchial secretions [1]. This enzyme is responsible for the fragmentation of extracellular deoxyribonucleic acid (DNA), which is derived from dead leucocytes and which contributes to the high viscosity of sputum [2].

The clinical efficacy of aerosolized rhDNase in the treatment of CF patients has been evaluated by several studies [3-10]. In two of them, large cohorts of patients have been treated for 24 weeks and more [7, 8]. The investigators found a sustained, statistically significant improvement of forced expiratory volume in one second (FEV1) by a mean of $6 \%$ over baseline values. In one of these studies, there was also a significant improvement of the patient's perception of dyspnoea and well-being. Furthermore, the results suggested that bronchial infection might be under better control while on treatment with rhDNase [7].

Current concepts in the pathogenesis of CF lung disease imply that a chronic inflammatory process leads to the gradual destruction of the bronchial walls, particularly those of bronchioles. Although this inflammatory process may antedate detectable signs of infection [11], there is no doubt that chronic infection, especially with Gram-negative rods, such as Pseudomonas aeruginosa, amplifies the process by recruitment of neutrophils and production of proinflammatory factors [12]. Activated neutrophils release large amounts of proteases, particularly elastase and cathepsin $\mathrm{G}$, and the resulting protease/ antiprotease imbalance is a major pathogenic factor in the tissue destruction that characterizes CF lung pathology [13-15].

In the airways, free elastase and cathepsin $G$ are inactivated, in part, by antiproteases, such as bronchial secretory leucoprotease inhibitor (SLPI) and alpha ${ }_{1}$-antitrypsin $[16,17]$, while another fraction of these cationic enzymes forms inactivated complexes with extracellular DNA, an anionic molecule [18]. In vitro treatment of sputum samples with deoxyribonuclease (DNase) has been shown to release significant amount of proteolytic activity, probably from these complexes [19]. Therefore, there is some concern that treatment with aerosolized rhDNase may cause a significant increase of proteolytic activity in the bronchial lumen, which might be deleterious for the patient's airways.

In order to study this question, sputum obtained from CF patients was analysed for the activity of neutrophil elastase and cathepsin $\mathrm{G}$, before and after institution of a regular treatment with aerosolized rhDNase, as well 
as before and after cessation of a 4-6 month course of this treatment. Because neutrophil elastase has been shown to induce expression of interleukin-8 (IL-8), a potent chemotactic factor for neutrophils, in bronchial epithelial cells [20], immunoreactive IL-8 and chemotactic activity were measured in the same sputum samples.

\section{Patients and methods}

\section{Patients}

Twelve CF patients at our institution (4 females and 8 males, aged $24 \pm 10$ yrs), who participated in a multicentre, open-labelled trial with rhDNase treatment $(2.5$ $\mathrm{mg}$ per aerosol once daily for several months) completed the present study as a supplement to the main trial. The study included four periods of $24 \mathrm{~h}$ sputum collection on an out-patient basis. It had been reviewed by the local, Ethics Committee, and all subjects gave informed consent. The patients were requested to collect sputum the day before initiation of treatment (Day 0), and on Day 15. After 4-6 months, rhDNase treatment was stopped. Sputum was collected again on the last day of treatment (Last), and one week later (Last+7). Patients were given the choice of participating in one or the other part of the study, or in both. Eight patients participated in the first part (Day 0 and Day 15), and eight patients in the second part (Last and Last+7).

Each patient had CF diagnosis confirmed by a sweat test. All had moderate to severe lung disease with FEV1 ranging $20-44 \%$ of predicted, and a median value of $33 \%$ pred. The National Institutes of Health (NIH) clinical score ranged 49-76, with a median value of 60 . All patients had chronic bronchial infection with $P$. aeruginosa, two patients additionally had Burkholderia cepacia, and four had Staphylococcus aureus. During the first part of the study (Day 0 to Day 15), as well as during the second part (Day Last to Day Last +7 ), the patients were in stable clinical condition with no clinical sign of exacerbation of their respiratory disease. This was also true for the two patients who were harbouring B. cepacia and who did not show particular worsening of pulmonary function tests or clinical status over the 6 month period covered by the study.

\section{Sputum collection}

Patients were instructed to collect morning sputum, evening sputum, and morning sputum again on the following day, each time after a drainage session. Aerosolized DNase (on Day 15 and on Day Last) was administered before the morning sputum of the first day, and not until after the morning sputum of the second day. Therefore, the three samples were representative of three drainage sessions over a $24 \mathrm{~h}$ period of time, following a single administration of the drug. Samples had to be stored immediately in the refrigerator, at $4-8^{\circ} \mathrm{C}$, and brought to the laboratory on the second day in a thermo-isolated bag. The samples were processed on the same day. In addition, patients had to collect all sputum that was expectorated between the drainage sessions, during daytime activities or during the night. These additional samples were not taken for laboratory analysis, but were used to determine the weight of $24 \mathrm{~h}$ sputum. The three refrigerated samples were pooled, mixed with an identical volume of sterile saline solution $(0.9 \% \mathrm{NaCl})$ and agitated for $1 \mathrm{~min}$ in a vortex mixer. A $1.5 \mathrm{~mL}$ aliquot was taken for quantitative bacteriology. The rest was centrifuged at $9,000 \times \mathrm{g}$. Supernatant was stored at $-70^{\circ} \mathrm{C}$ until tested, and the pellet was discarded.

\section{Leucocyte elastase and cathepsin $G$}

Human leucocyte elastase (HLE) activity was measured with N-methoxysuccinyl-Ala-Ala-Pro-Val-p-nitroanilide as a specific substrate, in a spectrophotometric assay, as described previously [21]. Elastase activity was defined as: 1 unit $(\mathrm{U})=1 \mu \mathrm{mol}$ p-nitroanilide hydrolysed $\cdot \mathrm{min}^{-1}$. Human leucocyte cathepsin G (HCG) was measured with a similar assay using N-methoxysuccinyl-Ala-Pro-Phep-nitroanilide as a specific substrate. In this assay: $1 \mathrm{U}=$ 1 nanomole of substrate hydrolysed $\cdot \mathrm{min}^{-1}$. These synthetic substrates (Calbiochem Behring, Luzern, Switzerland) have been shown to be specific for HLE and HCG, respectively [21].

\section{Chemotaxis assay}

The chemotactic activity of sputum for blood neutrophils isolated from healthy volunteers was measured according to a modification of the method by SHI et al. [22]. Neutrophils were obtained from buffy coats of normal healthy donors by dextran sedimentation and density gradient centrifugation (Hypaque-Ficoll). Dilutions of sputum supernatant $(1: 16)$ were placed in the lower well $\left(400 \mu \mathrm{L} \cdot \mathrm{well}^{-1}\right)$ of a 96 -well microtitre plate. The plate was inserted in a 96-well chemotaxis chamber (Neuroprobe; Cabin John, MD, USA). Neutrophils were pipetted in the upper wells $\left(10^{6}\right.$ in $\left.100 \mu \mathrm{L}\right)$, which are separated from the lower wells by polycarbonate filters with $3 \mathrm{~mm}$ pores. After completion of the migration of the cells toward the chemotactic stimulus of the lower well $\left(60 \mathrm{~min}\right.$ at $\left.37^{\circ} \mathrm{C}\right)$, the content of the upper wells was removed, replaced by $200 \mu \mathrm{L}$ ethylenediamine tetraacetic acid (EDTA) ( $2 \mathrm{mM})$ in phosphate-buffered saline (PBS), and incubated at $4^{\circ} \mathrm{C}$ for $20 \mathrm{~min}$. The EDTA solution was then aspirated, and the microtitre plate-filter assembly centrifuged at $1,800 \mathrm{rpm}$ for $10 \mathrm{~min}$. The filter was removed, fluid was aspirated carefully, not to disturb the neutrophil layer that had been pelleted at the bottom of the plate, and $150 \mu \mathrm{L}$ of buffer containing $2.5 \mu \mathrm{g} \cdot \mathrm{mL}^{-1}$ of 3-(4,5-dimethylthiazol-2-yl)-2,5diphenyl-tetrazolium bromide (MTT) was added. After incubation for $4 \mathrm{~h}$ at $37^{\circ} \mathrm{C}$, MTT was dissolved by addition of $150 \mu \mathrm{L}$ isopropanol, agitated overnight, and the plates were analysed with an enzyme-linked immunosorbent assay (ELISA) reader (Biorad, Richmond, CA, USA) at $550 \mathrm{~nm}$. The optical density was compared to that of a standard curve obtained with known amounts of neutrophils. Chemotactic activity was expressed as the number of neutrophils that migrated specifically, following exposure to sputum supernatant (chemotaxis), minus the number of neutrophils that migrated randomly in controls (chemokinesis). 
Interleukin-8 (IL-8) assay

IL-8 concentration in sputum supernatant (dilution $1: 1000$ ) was determined by ELISA (Innogenetics, Zwijndrecht, Belgium), according to the manufacturer's instructions. The limit of detection of this assay was $25 \mathrm{pg} \cdot \mathrm{mL}^{-1}$.

\section{Bacterial cultures}

The sample was treated with two parts of dithiothreitol, $2 \mu \mathrm{g} \cdot \mathrm{mL}^{-1}$ (Sigma, St Louis, MO, USA), centrifuged at 2,500 $\times \mathrm{g}$ and resuspended, in order to decrease the viscosity. Control experiments with suspensions of $P$. aeruginosa and $S$. aureus of known bacterial density, with and without dithiothreitol treatment, had shown no alteration of the final, quantitative, bacteriological result (data not shown). Four serial 10 fold dilutions of the specimen were prepared, and the last three dilutions were plated with a $10 \mu \mathrm{L}$ loop on culture media. Another set of media was plated with a $1 \mu \mathrm{L}$ loop of the lowest dilution. Culture media included blood-agar, CNA Columbia-agar, McConkey-agar, and B. cepacia selective-agar. Plates were incubated for 2-3 days. Bacterial species were identified using usual biochemical reactions. The colonies counted were multiplied by the dilution factor, and the final result (colony-forming units (cfu) $\cdot \mathrm{mL}^{-1}$ ) was adapted to the nearest potency of 10 .

\section{Statistical evaluation}

The results are given as mean \pm SEM. Paired values (Day 0 versus Day 15, and Day Last versus Day Last+7) were compared using the Wilcoxon nonparametric test. Differences were considered significant for $\mathrm{p}$-values less than 0.05. Changes in HLE, HCG, chemotaxis and IL8 were compared to each other by simple linear regression, with calculation of Pearson's correlation coefficient (r).

\section{Results}

\section{Amount of sputum}

Collection of $24 \mathrm{~h}$ sputum before and after institution of rhDNase treatment showed a trend toward a decrease in total amount, but this was not statistically significant (Day $0=71 \pm 19 \mathrm{~g}$ versus Day $15=53 \pm 11 \mathrm{~g} ; \mathrm{p}=$ $0.208)$. There was no change in sputum amount after stopping treatment (Day Last $=68 \pm 19 \mathrm{~g}$ versus Day last $+7=62 \pm 21 \mathrm{~g} ; \mathrm{p}=0.674)$.

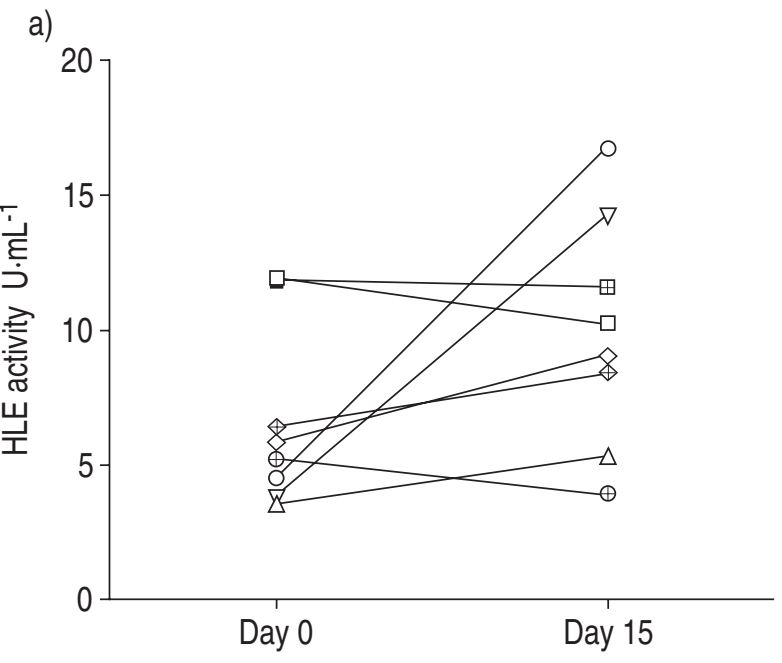

b)

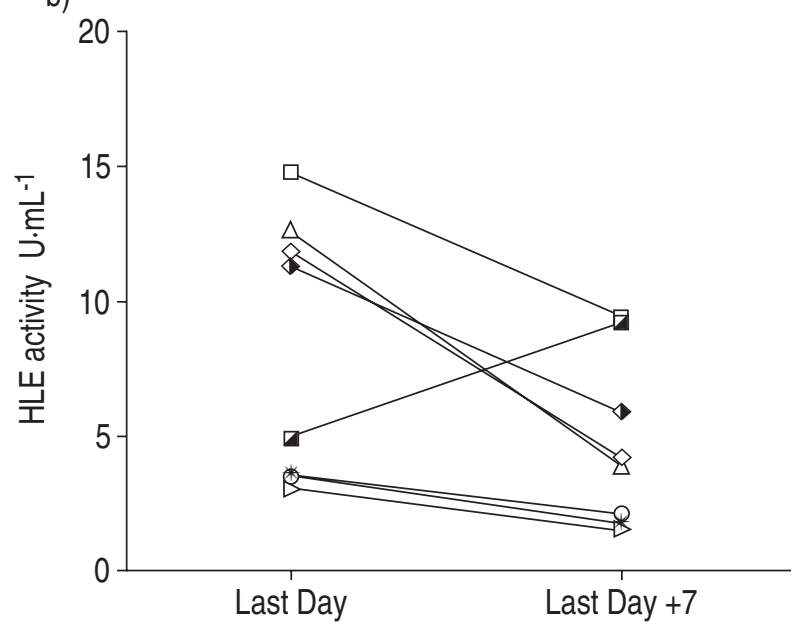

Fig. 1. - a) Individual values for sputum activity of human leucocytic elastase (HLE) before (Day 0), and 15 days (Day 15) after institution of q.d. treatment with aerosolized recombinant human deoxyribonuclease (rhDNase). b) Individual values for HLE on the last day of treatment (Last Day), and 7 days after discontinuation of rhDNase (Last Day +7 ). For HLE activity $1 \mathrm{U}$ corresponds to $1 \mu$ mole of substrate hydrolysed. $\mathrm{min}^{-1}$. See table 1 for mean values and statistics.

Activity of HLE and HCG, chemotactic activity of sputum and IL-8 concentration

Table 1 shows the means of HLE and HCG activity, chemotaxis and immunoreactive IL-8, before and after institution of rhDNase treatment, as well as before and after stopping treatment. Individual values are displayed in figure 1 for HLE, in figure 2 for HCG, and in figure 3 for chemotaxis.

Table 1. - Activity of human leucocyte elastase (HLE) and human leucocyte cathepsin G (HCG), chemotactic activity, and immunoreactive IL-8 in the sputum supernatant of CF patients

\begin{tabular}{lcccccc}
\hline & Day 0 & Day 15 & p-value* & Last Day & Last Day +7 & p-value* \\
\hline HLE activity U.mL-1 & $6.6 \pm 3.4$ & $9.9 \pm 4.3$ & 0.107 & $8.2 \pm 4.9$ & $4.6 \pm 3.2$ & 0.049 \\
HLE total activity U & $161 \pm 126$ & $280 \pm 212$ & 0.017 & $248 \pm 243$ & $61 \pm 72$ & 0.025 \\
HCG activity U.mL-1 & $19.3 \pm 8.5$ & $45.4 \pm 17.8$ & 0.025 & $38.2 \pm 18.6$ & $19.9 \pm 11.8$ & 0.036 \\
HCG total activity U & $564 \pm 174$ & $1266 \pm 355$ & 0.036 & $1054 \pm 371$ & $472 \pm 165$ & 0.069 \\
Chemotactic activity\# & $323 \pm 96$ & $370 \pm 169$ & 0.263 & $311 \pm 77$ & $311 \pm 78$ & 0.674 \\
IL-8 ng.mL-1 & $76.0 \pm 17$ & $69.0 \pm 10$ & 0.400 & $60.0 \pm 6$ & $72.0 \pm 13$ & 0.889 \\
\hline
\end{tabular}

*: Wilcoxon nonparametric test for paired values $(n=8)$; \#: chemotactic activity is expressed as the number of migrated neutrophils $\left(\times 10^{-3}\right)$. CF: cystic fibrosis; IL-8: interleukin- 8 . 
a)

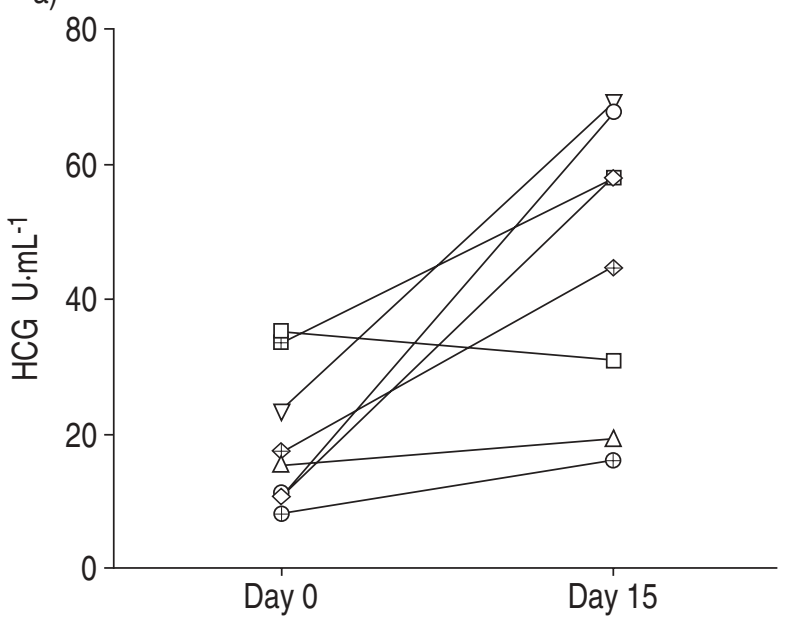

b)

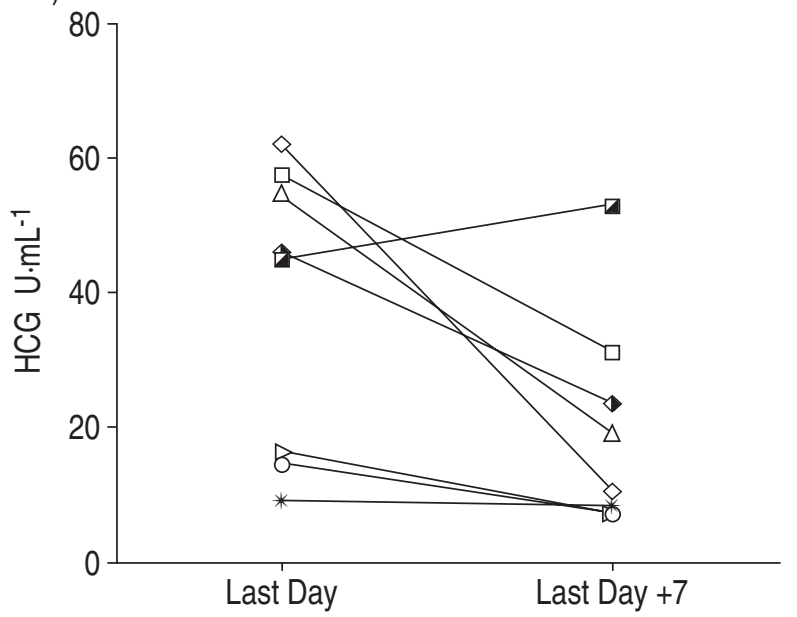

Fig. 2. - a) Individual values for sputum activity of human leucocytic cathepsin G (HCG) before (Day 0), and 15 days (Day 15) after institution of q.d. treatment with aerosolized rhDNase. b) Individual values for HCG on the last day of treatment (Last Day), and 7 days after discontinuation of recombinant human deoxyribonuclease (rhDNase) (Last Day +7). For HCG activity $1 \mathrm{U}$ corresponds to nmole of substrate hydrolysed $\cdot \mathrm{min}^{-1}$. See table 1 for mean values and statistics.

Fifteen days after starting treatment, we found increased HLE activity in the sputum of 5 out of 8 patients, and increased HCG activity in 7 out of 8 patients. The increase in HLE averaged $81 \pm 44 \%$ over the individual baseline values, but this difference did not reach statistical significance, whereas the increase in HCG averaged $189 \pm 70 \%$ and was statistically significant. Table 1 shows that when HLE and HCG activities are reported as the total activity in expectorated sputum from the three drainage sessions, the mean increase was statistically significant for both enzymes. By contrast, chemotaxis and IL- 8 concentration did not change.

One week after stopping a 4-6 months treatment, there was decreased HLE and HCG activity in the sputum of 7 out of 8 patients. For the group, HLE activity decreased by $35 \pm 18 \%$ and HCG by $43 \pm 11 \%$, which was statistically significant for both enzymes (table 1). Again, no significant change was observed in chemotactic activity and immunoreactive IL-8.

There was no correlation between HLE or HCG activities on the one hand, and chemotactic activity or immu-

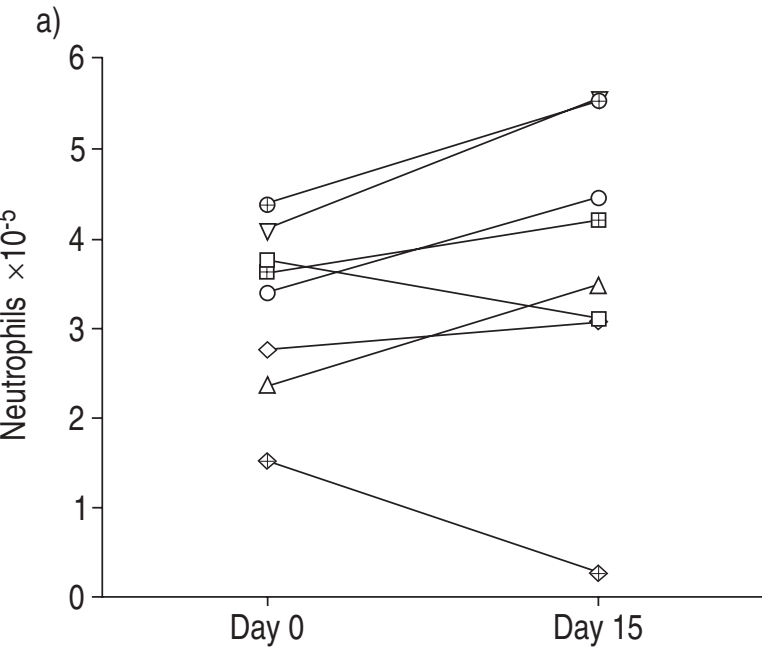

b)

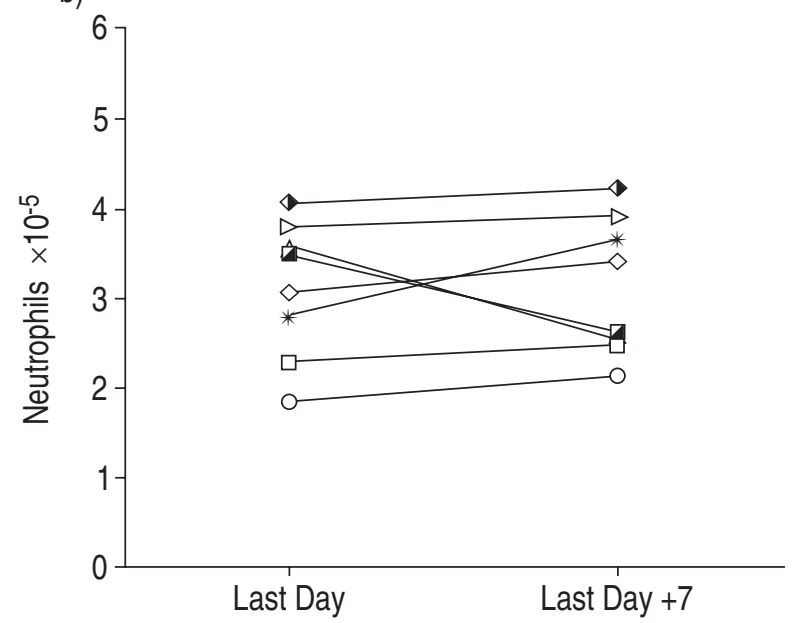

Fig. 3. - a) Individual values for sputum chemotactic activity before (Day 0), and 15 days (Day 15) after institution of q.d. treatment with aerosolized recombinant human deoxyribonuclease (rhDNase). b) Individual values on the last day under treatment (Last Day), and 7 days after discontinuation of rhDNase (Last Day +7 ). Chemotaxis is expressed on the ordinate as the number of neutrophils that have migrated during the assay minus the number of neutrophils that have migrated randomly in control experiments (chemokinesis). See table 1 for mean values and statistics.

noreactive IL-8 on the other. The same holds true when differences of HLE or HCG activities in paired samples (Day 0/Day 15 and Day Last/Day Last+7) were compared with differences in chemotactic activity or IL-8.

A linear correlation between difference in chemotactic activity and difference in immunoreactive IL- 8 were found when the 16 pairs of samples of both parts of the study were pooled (eight pairs of samples Day 0/Day 15, and eight pairs of samples Day Last/Day Last +7 ; $\mathrm{r}=0.605 ; \mathrm{p}=0.013$ ). This finding is not directly related to the objectives of the study, but supports the validity of the measurements: it is expected that a change in IL8 , a potent chemotactic factor, should be associated with a change in chemotactic activity.

\section{Quantitative sputum cultures}

Quantitative sputum cultures were available in 6 out of 8 patients for each part of the study. The number of 
$P$. aeruginosa ranged from $10^{7}$ to $10^{9} \mathrm{cfu} \cdot \mathrm{mL}^{-1}$ in sputum before starting rhDNase. After 2 weeks of treatment (Day 15), P. aeruginosa $\mathrm{cfu} \cdot \mathrm{mL}^{-1}$ decreased by 2 $\log$ in one case, by $1 \mathrm{log}$ in three cases, and did not change in two. One patient also had Proteus mirabilis infection, which increased from $10^{7}$ to $10^{9} \mathrm{cfu} \cdot \mathrm{mL}^{-1} . B$. cepacia was present in two patients. In one of them, it was found on a single occasion, and no more thereafter during more than 6 months of follow-up. The other patient was chronically infected with $B$. cepacia.

In the second part of the study, patients who had reached 4-6 months of treatment with rhDNase showed numbers of $P$. aeruginosa ranging from $10^{7}$ to $10^{8}$ $\mathrm{cfu} \cdot \mathrm{mL}^{-1}$ in sputum. One week after stopping treatment, there was a decrease by $2 \log$ in one case, by one log in two cases, and no change in three. Three patients had infection with $S$. aureus, from which two showed an increase and one a decrease of $\mathrm{cfu} \cdot \mathrm{mL}^{-1}$.

These results of quantitative bacteriology indicate that the changes of HLE and HCG activity, which we observed during the same period of time, could not be explained by exacerbations of the chronic bacterial infection. For instance, during the first part of the study, only one patient showed an increase in bacterial load (P. mirabilis), while most patients showed a decrease or no change in bacteria, together with definite increase in HLE and HCG. Inversely, during the second part of the study, nearly all patients had a decrease in HLE and HCG, while in most cases there was no relevant alteration in bacterial load.

Pulmonary function test, clinical score and markers of inflammation in sputum

FEV1 (\% pred) and NIH clinical scores did not correlate with any of the inflammation markers measured in the sputum supernatant of each patient (data not shown).

\section{Discussion}

Treatment of CF patients with daily aerosolized rhDNase has recently been introduced in the USA and Europe. This drug has been welcomed with understandable enthusiasm by patients, clinicians and researchers. It has been specifically designed for this disease, and appears to have a dramatic effect on the viscosity and stickiness of the purulent bronchial secretions that hamper the daily life of CF patients. Several, well-controlled studies have demonstrated the clinical benefit that can be expected from this treatment [3-10]. However, as recently noted in an editorial [23], there is so far no evidence that rhDNase may prevent the development of progressive lung damage.

When rhDNase was under investigation in clinical trials, a paper appeared in an abstract form, warning that extracellular DNA, a polyanion, binds and inactivates significant amounts of neutrophil elastase and cathepsin G, two cationic molecules [19]. When purulent sputum samples of patients were treated in vitro with purified pancreatic DNase, there was a nearly three fold increase in elastase activity, and a six fold increase in cathepsin G activity [19].
In $\mathrm{CF}$, evidence has accumulated showing that a chronic imbalance between free neutrophil proteases and the overwhelmed local inhibitors, particularly alpha ${ }_{1}$ antitrypsin and SLPI, plays a major role in the pathogenesis of damage to the airways [12]. Therefore, there might be some concern that increased protease activity in bronchial secretions could represent an unwanted side-effect of treatment with aerosolized rhDNase. It was the purpose of the present study to examine this question. Because of the simultaneous participation of the patients to an open-label, multicentre trial, it was not possible to conduct this particular study in a controlled, double-blinded fashion. However, in order to increase the relevance of the observation, enzyme activities, chemotactic activity and IL- 8 concentration were determined before/after institution of aerosolized rhDNase, as well as before/after discontinuation of the same treatment. The patients were clinically stable during both time periods.

Neutrophil elastase activity of sputum was indeed found to be increased in most patients 15 days after starting treatment. The increase was more pronounced for cathepsin $\mathrm{G}$ than for neutrophil elastase, consistent with the in vitro observation that proportionally more cathepsin $G$ than elastase is bound to DNA [19]. When treatment was discontinued, changes in the opposite direction, but of the same amplitude, were observed.

Changes in the level of neutrophil elastase in bronchial secretions have been studied by two different groups of investigators in response to antibiotic treatment. SUTER and co-workers [16] reported a decrease in total immunoreactive neutrophil elastase but no significant change in the activity of free elastase in sputum. In contrast, MEYER et al. [24] found a 56\% mean decrease in free neutrophil elastase in the bronchoalveolar lavage fluid of CF patients who underwent a 2 week course of antibiotics. Comparison of these results with those of the present study suggests that the differences of elastase and cathepsin $G$ activities that we observed, following institution or withdrawal of aerosolized rhDNase, could be of biological relevance.

In order to interpret the changes in the activity of neutrophil proteases in sputum correctly, it was important to monitor the level of bacterial infection. For this reason, quantitative bacteriology was performed on the same samples. After 15 days of treatment with rhDNase, there was a trend towards a decrease in bacterial density for $P$. aeruginosa, in the order of magnitude of $1 \mathrm{log}$ $\mathrm{cfu} \cdot \mathrm{mL}^{-1}$. We considered this result as a sign of stability rather than a real improvement of infection, because a change of bacterial density by 1 or $2 \log \mathrm{cfu} \cdot \mathrm{mL}^{-1}$ appears to be of questionable significance: when $\mathrm{CF}$ patients received i.v. antibiotics for pulmonary exacerbation, a mean decrease by $6 \mathrm{log} \mathrm{cfu} \cdot \mathrm{mL}^{-1}$ was reported [25]. Furthermore, in a controlled study, SмITH et al. [26] were unable to demonstrate that treatment with rhDNase significantly decreased bacterial density in sputum, as a consequence of facilitated clearance of respiratory secretions. Therefore, we may simply consider that quantitative bacteriology in the present study essentially demonstrated that the bacterial load in the airways of the patients was stable. Consequently, the rise in neutrophil proteases that was observed was not due to an exacerbation of chronic infection. Similarly, 
after discontinuation of rhDNase, bacterial density remained stable and could not account for the decrease in neutrophil elastase and cathepsin G.

A recent study by $\mathrm{SHAH}_{\mathrm{H}}$ and co-workers [27] similarly addressed the question of increased sputum HLE in CF patients, after treatment with aerosolized rhDNase. They found an increase in HLE activity after 1 day of treatment, but not later on. Surprisingly, a slight but statistically significant decrease was found after 4 and 12 weeks, but no significant change from baseline after 24 weeks. The authors concluded that longer term therapy with rhDNase reduced the proteolytic activity of sputum. Their results are clearly at variance with those of the present study, which showed that stopping treatment after several months resulted in decreased HLE and HCG activity in sputum. Reasons for these diverging results may be multiple as the design of both studies was notably different. In particular, SHAH and co-workers [27] collected only one sputum specimen per day, and there was no attempt to measure the activity of HCG. Although the number of patients enrolled was high in their study, a third of them had to be excluded from the results because of intercurrent infection during the period of comparison.

The presence of free, active neutrophil proteases in sputum is a characteristic feature of $\mathrm{CF}$, and has not been found to the same extent in patients with chronic bronchitis or with bronchiectasis of other origin than $\mathrm{CF}[14,24]$. Moreover, the role of neutrophil proteases in the pathogenesis of $\mathrm{CF}$ lung disease is supported by several studies. BRUCE et al. [15] found increased elastolytic activity in sputum of $\mathrm{CF}$ patients together with increased excretion of urine desmosine, a degradation product of elastin, as compared with normal controls. They also reported that urine desmosin levels were negatively correlated to chest radiography score in these patients, and found abnormal, fragmented and exfoliated elastin fibres in the bronchial wall of autopsied patients with CF.

Other studies have shown the possible role of neutrophil proteases in favouring chronic bronchial infection. SUTER and co-workers [13] demonstrated that neutrophil elastase as well as cathepsin $\mathrm{G}$ have significant fibronectin cleaving activity, which facilitates the adhesion of Gram-negative bacteria to epithelial cells. PLOTKOWSKI et al. [28] showed that adherence of $P$. aeruginosa is increased by pretreatment of bronchial epithelium with neutrophil elastase. In addition, by cleaving opsonins such as C3 [14] and immunoglobulin G (IgG) [29], as well as opsonin receptors [30], an excess of neutrophil elastase can inhibit efficient phagocytosis of microorganisms. Finally, recent work by NAKAMURA et al. [20] has shown that neutrophil elastase induces IL-8 gene expression in a human bronchial epithelial cell line, and that elevated IL-8 levels in bronchoalveolar lavage fluid from CF patients can be decreased by treatment with aerosolized recombinant secretory leucoprotease inhibitor [31]. IL-8 is a cytokine with potent chemotactic activity for neutrophils, and an increased, local production of IL-8 in consequence to stimulation by neutrophil elastase could be one important mechanism maintaining chronic inflammation in the bronchial lumen in CF [32].

Among all the possible side-effects of increased activity of neutrophil proteases in the bronchial lumen, we were concerned that stimulation of additional neutrophil recruitment, for example via IL-8, would be one sideeffect with the most deleterious potential. Therefore sputum samples of the patients were examined for chemotactic activity. Treatment with rhDNase did not appear to alter chemotactic activity, nor did it alter IL-8 level in sputum. Thus, there was no evidence of a proinflammatory effect resulting from treatment with rhDNase.

It remains that other, more direct effects of increased neutrophil protease activity in the bronchial lumen, such as degradation of structural proteins or decreased efficacy of opsonization and phagocytosis, could be of concern in patients with cystic fibrosis who undergo long-term treatment with recombinant human deoxyribonuclease. The results of the present study show that this risk should be taken into account. Further studies are needed to establish whether the increase in neutrophil protease activity that we observed is clinically relevant. On the other hand, the development of new treatments with aerosolized antiproteases, such as recombinant secretory leucoprotease inhibitor, for which encouraging results have recently been reported [31], may offer interesting prospects, for example as a combination therapy with recombinant human deoxyribonuclease.

\footnotetext{
Acknowledgements: The authors are indebted to P. Rohner for his valuable advice in computing the data and
} to F. Rodrigez for excellent technical assistance.

\section{References}

1. Shak S, Capon DJ, Helmiss R, Marsters SA, Baker CL. Recombinant human DNase I reduces the viscosity of cystic fibrosis sputum. Proc Natl Acad Sci USA 1990; 87: 9188-9192.

2. Chernick WS, Barbero GJ. Composition of tracheobronchial secretions in cystic fibrosis of the pancreas and bronchiectasis. Pediatrics 1959; 24: 739-745.

3. Aitken ML, Burke W, McDonald G, Shak S, Montgomery $\mathrm{AB}$, Smith A. Recombinant human DNase inhalation in normal subjects and patients with cystic fibrosis. JAMA 1992; 267: 1947-1951.

4. Hubbard RC, McElvaney NG, Birrer P, et al. A preliminary study of aerosolized recombinant human deoxyribonuclease I in the treatment of cystic fibrosis. $N$ Engl J Med 1992; 326: 812-815.

5. Ramsey BW, Astley SJ, Aitken ML, et al. Efficacy and safety of short-term administration of aerosolized recombinant human deoxyribonuclease in patients with cystic fibrosis. Am Rev Respir Dis 1993; 148: 145-151.

6. Ranasinha C, Assoufi B, Shak S, et al. Efficacy and safety of short-term administration of aerosolised recombinant human DNase I in adults with stable stage cystic fibrosis. Lancet 1993; 342: 199-202.

7. Fuchs HJ, Borowitz DC, Christiansen DH, et al. Effect of aerosolized recombinant human DNase on exacerbations of respiratory symptoms and on pulmonary function in patients with cystic fibrosis. N Engl J Med 1994; 331: 637-642.

8. Shah PL, Scott SF, Fuchs HJ, Geddes DM, Hodson ME. Medium term treatment of stable stage cystic fibrosis with recombinant human DNase I. Thorax 1995; 50: 333-338. 
9. Shah PI, Bush A, Canny GJ, et al. Recombinant human DNase I in cystic fibrosis patients with severe pulmonary disease: a short-term, double-blind study followed by six months open-label treatment. Eur Respir J 1995; 8: 954-958.

10. Hodson ME, Shah PL. DNase trials in cystic fibrosis. Eur Respir J 1995; 8: 1786-1791.

11. Kahn TZ, Wagener JS, Bost T, Martinez J, Accurso FJ, Riches DWH. Early pulmonary inflammation in infants with cystic fibrosis. Am J Respir Crit Care Med 1995; 151: 1075-1082.

12. Suter S. New perspectives in understanding and management of the respiratory disease in cystic fibrosis. Eur J Pediatr 1994; 153: 144-150.

13. Suter S, Schaad UB, Morgenthaler JJ, Chevallier I, Schnebli HP. Fibronectin-cleaving activity in bronchial secretions of patients with cystic fibrosis. J Infect Dis 1988; 158: 89-100.

14. Suter S, Schaad UB, Roux L, Nydegger UE, Waldvogel FA. Granulocyte neutral proteases and Pseudomonas elastase as possible causes of airway damage in patients with cystic fibrosis. J Infect Dis 1984; 149: 523-531.

15. Bruce MC, Poncz L, Klinger JD, Stern RC, Tomshefsky JF, Dearborn DG. Biochemical and pathologic evidence for proteolytic destruction of lung connective tissue in cytic fibrosis. Am Rev Respir Dis 1985; 132: 529-535.

16. Suter S, Schaad UB, Tegner H, Ohlsson K, Desgrandchamps D, Waldvogel FA. Levels of free granulocyte elastase in bronchial secretions from patients with cystic fibrosis: effect of antimicrobial treatment against Pseudomonas aeruginosa. J Infect Dis 1986; 153: 902-909.

17. Suter S, Chevallier I. Proteolytic inactivation of $\alpha_{1^{-}}$ proteinase inhibitor in infected bronchial secretions from patients with cystic fibrosis. Eur Respir J 1991; 4: 40-49.

18. Potter JL, Mathews LW, Spector S, Lemm J. Complex formation between basic antibiotics and deoxyribonucleic acid in human pulmonary secretions. Pediatrics 1965; 36: 714-720.

19. Kueppers F, Fiel SB. Proteolytic activity of purulent secretions in patients with $\mathrm{CF}$ and bronchitis is increased by DNase. Am Rev Respir Dis 1992; 145: A563.

20. Nakamura H, Yoshimura K, McElvaney NG, Crystal RG. Neutrophil elastase in respiratory epithelial lining fluid of individuals with cystic fibrosis induces interleukin- 8 gene expression in a human bronchial epithelial cell line. J Clin Invest 1992; 89: 1478-1484.

21. Nakajima K, Powers JC, Ashe BM, Zimmermann M.
Mapping the extended substrate binding site of cathep$\sin \mathrm{G}$ and human leukocyte elastase: studies with peptide substrates related to the $\alpha_{1}$-protease inhibitor reactive site. J Biol Chem 1979; 254: 4027-4032.

22. Shi Y, Kornovski BS, Savani R, Turley EA. A rapid, multiwell colorimetric assay for chemotaxis. J Immunol Methods 1993; 164: 149-154.

23. Range SP, Knox AJ. rhDNase in cystic fibrosis. Thorax 1995; 50: 321-322.

24. Meyer KC, Lewandoski JR, Zimmerman JJ, Nunley D, Calhoun WJ, Dopico GA. Human neutrophil elastase

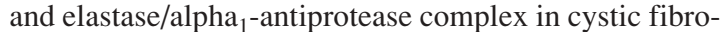
sis. Am Rev Respir Dis 1991; 144: 580-585.

25. Regelmann WE, Elliott GR, Warwick WJ, Clawson CC. Reduction of sputum Pseudomonas aeruginosa density by antibiotics improve lung function in cystic fibrosis more than do bronchodilators and chest physiotherapy alone. Am Rev Respir Dis 1990; 141: 914-921.

26. Smith A, Pepe M, Morlin G, Williams-Warren J, Ramsey B. Effect of rhDNase administration on sputum bacterial density. Pediatr Pulmonol 1994; (Suppl. 10): 163.

27. Shah PL, Scott SF, Knight RA, Hodson ME. The effects of recombinant human DNase on neutrophil elastase activity and interleukin- 8 levels in the sputum of patients with cystic fibrosis. Eur Respir J 1996; 9: 531-534.

28. Plotkowski MC, Beck G, Tournier JM, Bernardo-Filho M, Marques EA, Puchelle E. Adherence of Pseudomonas aeruginosa to respiratory epithelium and the effect of leucocyte elastase. J Med Microbiol 1989; 30: 285-293.

29. Fick RB, Naegel GP, Squier SU, Wood RE, Gee JBL, Reynolds HA. Proteins of the cystic fibrosis respiratory tract: fragmented immunoglobulin $\mathrm{G}$ opsonic antibody causing defective opsono-phagocytosis. J Clin Invest 1984; 74: 236-248.

30. Tosi MF, Zakem H, Berger M. Neutrophil elastase cleaves C3bi on opsonized Pseudomonas as well as CR1 on neutrophils to create a functionally important opsonin receptor mismatch. J Clin Invest 1990; 86: 300-308.

31. McElvaney NG, Nakamura H, Birrer P, et al. Modulation of airway inflammation in cystic fibrosis: in vivo suppression of interleukin-8 levels on the respiratory epithelial surface by aerosolization of recombinant secretory leukoprotease inhibitor. J Clin Invest 1992; 90: 1296-1301.

32. Richman-Eisenstat JBY, Jorens PG, Hébert CA, Ueki I, Nadel JA. Interleukin-8: an important chemoattractant in sputum of patients with chronic inflammatory airway disease. Am J Physiol 1993; 264: L414-L418. 